\title{
Syntheses and Biological Activities of 1-O-Glucopyranosyl Fatty Acid Esters
}

\author{
Akira K. Tanaka, Akio Kobayashi and Kyohei Yamashita \\ Department of Agricultural Chemistry, Faculty of Agriculture, \\ Tohoku University, Sendai
}

Received July 3, 1979

\begin{abstract}
1-O-Palmitoyl-D-glucopyranose was prepared by the selective 1-O-acylation of $4,6-O$ benzylideneglucose followed by hydrogenolysis of the protecting group. 1-O-Oleoyl-Dglucopyranose was synthesized from the corresponding benzylidene derivative by selective hydrolysis in acetic acid. This procedure constitutes a useful method for the synthesis of 1-O-acyl-D-glucopyranoses containing unsaturated carboxylic acids. However, 4,6-O-benzylidene-1-O-linolenoyl-D-glucopyranose was converted to 3-O-linolenoyl-D-glucopyranose by the acidic hydrolysis due to acyl migration.

Synthesized glucosyl esters were inactive in the bean second-internode bioassay. However, it was found that 3-O-linolenoyl-D-glucopyranose had a promoting activity on germination of pollen and growth of pollen tube.
\end{abstract}

Several 1-O-acyl-D-glucopyranoses with biological activities are found in nature. Brassins were isolated from rape (Brassica napus L.) pollen as growth-promoting substances for beans by J. W. Mitchell ${ }^{12}$ et al. in 1970, and the constituents of them were estimated as a series of 1- $\beta$-D-glucopyranosyl esters (1) of various fatty acids, mainly linolenic acid. ${ }^{2 !}$ Recently, it was reported ${ }^{3)}$ that glucosyl esters contained in rape pollen were not 1-esters but 6-esters, and these esters were inactive in the bean second-internode bioassay.

In general, it is troublesome to synthesize 1-D-glucopyranosyl ester of unsaturated fatty acids. Up to date syntheses of 1-glucosyl esters of gibberellin $\mathrm{A}_{3}$, abscisic acid and some phenolic acids were rare instances with success. In previous work, we reported ${ }^{4}$ the synthesis of 2,4-D 1-glucosyl ester which was one of the metabolite of 2,4-dichlorophenoxyacetic acid in plant. In this paper we wish to describe the synthesis of 1-O-fatty acyl glucopyranose (1), the unusual rearrangement of 1-O-linolenoylglucopyranose (1c) and the biological activity of glucosyl esters to plants.

In our previous report 2,4-D glucosyl ester was synthesized by the hydrogenation of 4,6$O$-benzylidene-1-O-(2,4-dichlorophenoxyacetyl)
D-glucopyranose, but this method was inappli cable to the synthesis of unsaturated glucosyl ester. Therefore we tried to obtain glucosyl esters by hydrolytic removal of benzylidene group in an acidic condition, because acetal groups should be removed in mild acidic conditions. ${ }^{5 !}$

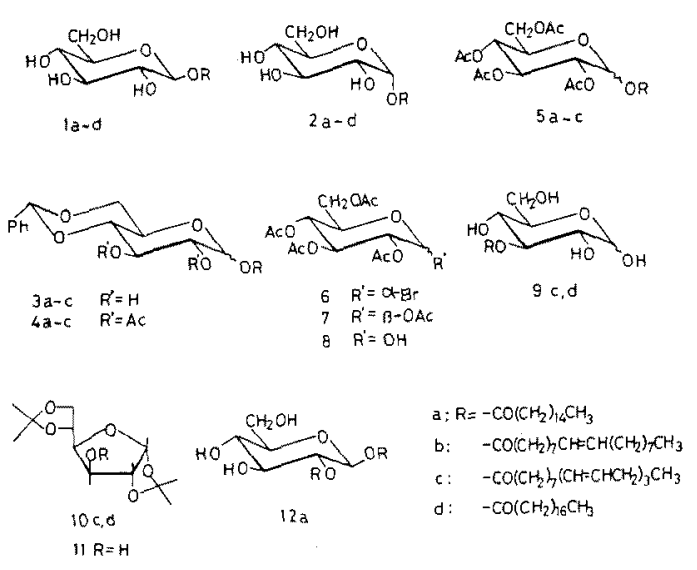

As a preliminary experiment, 1- $O$-palmitoyl$\beta$-D-glucopyranose (1a) was synthesized. A mixture of anomers of 4,6-O-benzylidene-1-Opalmitoyl-D-glucopyranose (3a) was prepared from sodium salt of 4,6-O-benzylidene-Dglucopyranose ${ }^{6\rangle}$ and palmitoyl chloride. The 
ratio of $\alpha$-and $\beta$-ester was determined as $1: 9$, respectively, from relative intensities of anomeric proton signals on PMR spectra $(\delta 6.41$, $\mathrm{d}, J=3.5 \mathrm{~Hz}$ for $\alpha$ and $5.52, \mathrm{~d}, J=7.5 \mathrm{~Hz}$ for $\beta$ ) and their diacetate (42) was a mixture of $\alpha$ and $\beta$-esters in a ratio of $1: 9$, too. The $\beta$ anomer was isolated from the mixture by recrystallization, and converted to 1-O-palmitoyl- $\beta$-D-glucopyranose (1a) by hydrogenolysis in quantitative yield. The $\beta$-ester $\mathbf{1 a}$ and its acetate (4a) were identical in all respect with the authentic samples. ${ }^{7,8)}$

Debenzylidenation of 4,6-O-benzylidene-1$O$-palmitoyl- $\beta$-D-glucopyranose $(\beta-3 a)$ by hydrolysis with $50 \%$ aqueous acetic acid at $95^{\circ} \mathrm{C}$ for $1 \mathrm{hr}$ afforded 1- $O$-palmitoyl- $\beta$-Dglucopyranose (1a) in about $10 \%$ yield. This method seemed applicable to the synthesis of 1-O-acyl-D-glucopyranose containing unsaturated carboxylic acids such as oleic and linolenic acid. Thus the benzylidene-glucosyl esters of oleic and linolenic acid were synthesized by the same procedure as described above. In the previous report it was found that in the acylation of benzylideneglucose with 2,4-D $D^{4}$ the $\alpha$ ester was formed predominantly when excess sodium salt was used, and the $\beta$-ester was yielded predominantly using excess acyl chloride. Similar tendency was observed in the synthesis of fatty acid esters.

4,6-O-Benzylidene-1-O-oleoyl - D - glucopyranose (3b) was hydrolyzed with aqueous acetic acid in a similar condition as described for palmitate to afford 1-O-oleoyl-D-glucopyranose $(\mathbf{1 b}, \mathbf{2 b})$. The structure of them was confirmed by the comparison of the chemical shifts of anomeric proton signals $(\alpha, \delta 6.45 ; \beta, \delta 5.26)$ with those of palmitate $(\mathbf{2 a}, \mathbf{1 a})(1-\alpha, \delta 6.30$; $1-\beta, \delta 5.37$ ) (Table II), and the anomeric distribution was unchanged with starting materials (3b). The tetraacetyl derivatives of $\mathbf{1 b}$ and $\mathbf{2 b}$ were compatible with the authentic samples prepared from acetobromoglucose. These results show the usefulness of this procedure to obtain the glucosyl esters of unsaturated carboxylic acids.

In the next place, 4,6-O-benzylidene-1-Olinolenoyl-D-glucopyranose(3c) was hydrolyzed in the same condition. The product obtained in $25 \sim 60 \%$ yield showed different signal pattern on PMR spectra from those of 1-glucosyl esters of palmitic acid or oleic acid. It was suggested that the linolenate was not 1-ester because anomeric proton signals of it were ob-

Table I. Stereochemical Distribution of Esterification Products of 4,6-O-BEnZyLIDENE-D-gluCopyranose as a Function of pH

\begin{tabular}{|c|c|c|c|c|c|c|c|c|}
\hline \multirow{3}{*}{ No. } & \multirow{3}{*}{ Ester group } & \multirow{3}{*}{$\begin{array}{c}\text { Yield } \\
(\%)\end{array}$} & \multirow{3}{*}{$\mathrm{pH}$} & \multirow{3}{*}{$\alpha: \beta$} & \multicolumn{4}{|c|}{ Chemical shift of anomeric protons } \\
\hline & & & & & \multicolumn{2}{|c|}{ OH free (3) } & \multicolumn{2}{|c|}{ Diacetate (4) } \\
\hline & & & & & $\alpha$ & $\beta$ & $\alpha$ & $\beta$ \\
\hline 1 & Palmitate & 18 & 5 & $1: 9$ & 6.41 & 5.52 & 6.27 & 5.77 \\
\hline 2 & Palmitate & 7 & 7 & $3: 1$ & & & & \\
\hline 3 & Oleate & 14 & 5 & $1: 5$ & & & 6.46 & 5.85 \\
\hline 4 & Linolenate & 19 & 6 & $1: 1$ & 6.23 & 5.58 & 6.29 & 5.71 \\
\hline
\end{tabular}

Table II. Debenzylidenation Product of 1-O-Acyl-4,6-O-benzylidene-d-glucopyranose

\begin{tabular}{|c|c|c|c|c|c|c|c|c|}
\hline \multirow{3}{*}{ Ester group } & \multirow{3}{*}{$\begin{array}{c}\text { Anomeric } \\
\text { ratio of } 3 \\
\alpha: \beta\end{array}$} & \multirow{3}{*}{$\begin{array}{c}\text { Concentration } \\
\text { of } \mathrm{AcOH} \\
(\%)\end{array}$} & \multirow{3}{*}{$\begin{array}{c}\text { Yield } \\
(\%)\end{array}$} & \multicolumn{5}{|c|}{ Chemical shifts of anomeric protons } \\
\hline & & & & \multirow{2}{*}{$\begin{array}{l}\text { Anomeric } \\
\text { ratio } \\
\alpha: \beta\end{array}$} & \multicolumn{2}{|c|}{$\mathrm{OH}$ free } & \multicolumn{2}{|c|}{$\begin{array}{c}\text { Tetraacetate } \\
(\mathbf{5})\end{array}$} \\
\hline & & & & & $\begin{array}{c}(2) \\
\alpha\end{array}$ & $\stackrel{(1)}{\beta}$ & $\alpha$ & $\beta$ \\
\hline \multirow[t]{2}{*}{ Palmitate } & $-: 100$ & 70 & 10 & $-: 100$ & & 5.37 & & 5.73 \\
\hline & $3: 1$ & - & & $3: 1$ & 6.30 & & 6.20 & \\
\hline Oleate & $1: 5$ & 50 & 10 & $1: 5$ & 6.45 & 5.26 & 6.26 & 5.75 \\
\hline \multirow[t]{2}{*}{ Stearate } & $1: 1$ & 50 & 60 & $1: 1$ & 5.14 & 4.53 & 6.29 & 5.65 \\
\hline & $-: 100$ & & 25 & $1: 1$ & & & & \\
\hline
\end{tabular}

\footnotetext{
* The protective group was removed by hydrogenation.
} 
served at higher field than those of 1-O-palmitate or 1-O-oleate and on acetylation these signals were shifted remarkably to lower field. This fact was further confirmed by the degradation reactions as follows.

It was known that penta- $O$-acyl-glucose could be converted to 1-bromide by treatment with hydrobromic acid in acetic acid as illustrated in a synthesis of acetobromoglucose ${ }^{9 !}$ (6) from penta- $O$-acetylglucose (7). If the hydrolyzed product of the linolenate was 1-Olinolenoyl-D-glucopyranose (1c) it must be converted to acetobromoglucose (6) and which could be changed to $2,3,4,6$-tetra- $O$-acetyl-Dglucopyranose $^{(0)}(8)$ by treatment with silver carbonate. But in practice neither tetraacetylglucose nor linolenic acid could be detected in the degradation products of the linolenoyl derivatives.

Comparison of the PMR spectrum of the trimethylsilyl derivative of linolenoylglucose with those of 1- $\alpha$ (2a), 1- $\beta$ (1a), 2- and 6-palmitoyl glucopyranose showed the location of linolenoyl group to be neither 1,2 nor 6 . The proton signals of linolenate at $\delta 4.94(\mathrm{~d}$, $J=3.5 \mathrm{~Hz})$ and $4.48(\mathrm{~d}, \mathrm{~d}, J=7.5, J=2 \mathrm{~Hz})$ were assigned to $\alpha$ - and $\beta$-anomeric protons, respectively, from their coupling constant, and other signals at $\delta 4.96(\mathrm{t}, J=9.0 \mathrm{~Hz})$ and 4.75 $(\mathrm{t}, J=9.0 \mathrm{~Hz})$ were attributable to protons attached to the esterified carbon from their low field shifts. By the irradiation at 3.33 $\mathrm{ppm}$, the signals of $\beta$-anomeric proton (4.48 $\mathrm{ppm}$ ) and $4.75 \mathrm{ppm}$ were changed to broad singlet, respectively, and by the irradiation at $3.54 \mathrm{ppm} \quad$ (d,d, $J=3.5, \quad J=9.0 \mathrm{~Hz}, \quad \mathrm{C}-2 \mathrm{H}$ ), which was not overlapped with other signals, the signals of $\alpha$-anomeric proton and signal at $4.96 \mathrm{ppm}$ were decoupled. These results clearly showed that this ester was 3-O-linolenoyl-D-glucopyranose $(9 \mathrm{c})$, because the decoupled positions by the irradiation at $\mathrm{C}-2$ proton were anomeric proton and $\mathrm{C}-3$ proton.

These estimation was supported by the ${ }^{13} \mathrm{C}$ NMR data as follows. Vignon and Vottero ${ }^{11}$ found that, in the CMR spectra of 3-O-acetylD-glucopyranose, esterified carbon signal was appeared at down field and adjacent two carbons were shifted to upper field. The carbon signals due to sugar moiety in linolenoyl glucose were assigned by using Vignon's data as shown in Table III. It was confirmed that the difference of chemical shift of each carbon signal of linolenoyl glucose from the corresponding carbon signal of glucose, which were measured in the same condition, was in good agreement with the data of 3- $O$-acetyl-Dglucopyranose.

Finally the structure of the linolenate was confirmed by the unambigueous synthesis ${ }^{12}$ of 3-O-linolenoyl-D-glucopyranose (9c). 1,2; 5,6Di- $O$-isopropylidene-3- $O$-linolenoyl-D-glucofuranose (10c) which was derived from 1,$2 ; 5,6$ $\mathrm{di}-O$-isopropylidene-D-glucofuranose ${ }^{13 \text { ? }}$ was converted to 3-O-linolenoyl-D-glucopyranose $(9 \mathrm{c})$. The IR and NMR spectra of the linolenate was in good agreement with that of synthesized 9c. Furthermore 3-O-stearoyl-Dglucopyranose (9d) derived from the linolenate (9c) by hydrogenation showed no depression of melting point upon admixture with authentic 9d. Thus the structure of linolenoyl ester prepared from benzylidene derivative by hydrolysis was confirmed to be 3-O-linolenoyl-D-gluco-

Table III. Chemical Shifts of ${ }^{13} \mathrm{C}$ on Glucopyranose Ring

\begin{tabular}{|c|c|c|c|c|c|c|c|c|c|c|c|c|}
\hline \multirow[b]{2}{*}{$\left(\mathrm{DMSO}-d_{\theta}+\mathrm{D}_{2} \mathrm{O}\right)$} & \multicolumn{6}{|c|}{$\alpha$-Form } & \multicolumn{6}{|c|}{$\beta$-Form } \\
\hline & $\mathrm{C}-1$ & $\mathrm{C}-2$ & $\mathrm{C}-3$ & $\mathrm{C}-4$ & $\mathrm{C}-5$ & $C-6$ & $\mathrm{C}-1$ & $\mathrm{C}-2$ & $\mathrm{C}-3$ & $C-4$ & $\mathrm{C}-5$ & $\mathrm{C}-6$ \\
\hline 3-O-Linolenoyl glucose & 93.5 & 71.7 & 76.8 & 69.7 & 73.1 & 62.4 & 97.9 & 74.1 & 78.9 & 69.7 & 77.5 & 62.4 \\
\hline Glucose & 93.5 & 73.4 & 74.4 & 71.6 & 73.1 & 62.5 & 97.9 & 76.0 & 77.7 & 71.6 & 77.7 & 62.5 \\
\hline Difference & 0 & -1.7 & +2.4 & -1.9 & 0 & -0.1 & 0 & -1.9 & +1.2 & -1.9 & -0.2 & -0.1 \\
\hline $\begin{array}{c}\left(\mathrm{D}_{2} \mathrm{O}\right) \\
\text { 3-O-Acetyl glucose }\end{array}$ & & & & & & & & & & & & 618 \\
\hline $\begin{array}{l}\text { 3-O-Acetyl glucose } \\
\text { Glucose }\end{array}$ & 93.2 & 71.0 & 76.6 & 69.0 & 72.4 & 61.5 & 97.0 & 73.4 & 78.6 & 69.0 & 76.9 & 61.8 \\
\hline $\begin{array}{l}\text { Glucose } \\
\text { Difference }\end{array}$ & 93.4 & 72.7 & 74.1 & 71.0 & 72.7 & 62.0 & 97.2 & 75.4 & 77.2 & 71.0 & 77.1 & 62.1 \\
\hline Difference & -0.2 & -1.7 & +2.5 & -2.0 & -0.3 & -0.5 & -0.2 & -2.0 & +1.4 & -2.0 & -0.2 & -0.3 \\
\hline
\end{tabular}


pyranose (9c). The acyl migration from 1-O to 3-O in glucosyl esters has not been known so far.

Although we could not obtain 1-O-linolenoyl-D-glucopyranose, the following synthetic glucosyl esters were nevertheless evaluated in the bean second-internode bioassay and all failed to exhibit brassins-type activity ${ }^{14} ; 1-O$ palmitate $(\alpha: \beta=3: 1) ; 1-O$-oleate $(\alpha: \beta=1: 5)$ and 3-O-linolenate $(\alpha: \beta=1: 1)$.

Effects of 3-O-linolenoyl-D-glucopyranose (9c) on germination of pollen and growth of pollen tube were tested using tobacco (Nicotiana tabacum L.) and rape (Brassica napus L.) in isotonic $8 \mathrm{M}$ sucrose solution. ${ }^{15)}$ As presented in Fig. 1, linolenate in a concentration range of $10 \sim 10^{-4} \mathrm{ppm}$ promoted the germination of tobacco pollen and the elongation of pollen tube, although it inhibited at a concentration above $100 \mathrm{ppm}$. At the concentration of $10^{-2}$ ppm germination rate of pollen showed a $38 \%$ increase over control, and the number of pollens with elongated pollen tube showed a $135 \%$ increase over control. On the rape pollen linolenate showed stimulating activity similar to that on tobacco pollen.

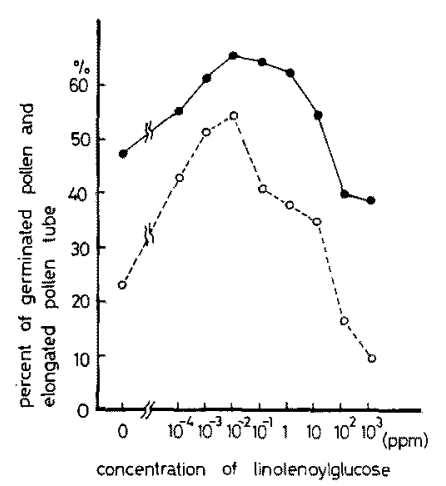

FIG. 1. Effect of 3-O-Linolenoyl-D-Glucopyranose on Growth of Tobacco Pollen.

--o, germinated pollen; $\bigcirc--\bigcirc$, pollen with elongated pollen tube.

\section{EXPERIMENTAL}

All melting points were uncorrected. NMR spectra were recorded at $100 \mathrm{MHz}$ or $60 \mathrm{MHz}$ with TMS as an internal standard. Thin-layer chromatography (TLC) was carried out with silica gel $\mathrm{H}(0.2 \mathrm{~mm})$ on plate $(50 \times 200 \mathrm{~mm})$, and preparative TLC was carried out with silica gel PF $(0.75 \mathrm{~mm})$ on plate $(200 \times 200 \mathrm{~mm})$.

1-O-Palmitoyl-4,6-O-benzylidene-D-glucopyranose(3a). Dry sodium salt of 4,6-O-benzylidene glucose $\left.{ }^{8}\right)(15.6 \mathrm{~g}$, $54.6 \mathrm{mmol}$ ) was suspended in $100 \mathrm{ml}$ of dry tetrachloroethane and was treated with $14.8 \mathrm{~g}$ of palmitoyl chloride ( 54 mmol) dissolved in $25 \mathrm{ml}$ of tetrachloroethane. After stirring for $24 \mathrm{hr}$ at room temperature $10 \mathrm{ml}$ of dry methanol was added and insoluble material was filtered off. The filtrate was concentrated in vacuo and the residue was extracted with hexane to remove methyl palmitate. The residue was dissolved in chloroform, and a small amount of insoluble material was filtered off. The filtrate was concentrated and chromatographed on silica gel $(300 \mathrm{~g})$ using benzene-ethyl acetate $(7: 3)$ as an eluent to yield $5 \mathrm{~g}(18 \%)$ of anomeric mixture of 3a. PMR $\delta\left(\mathrm{CDCl}_{3}\right): 6.41(0.1 \mathrm{H}, \mathrm{d}$, $J=3.5 \mathrm{~Hz}, a$-anomeric proton), $5.77(0.9 \mathrm{H}, \mathrm{d}, J=$ $7.5 \mathrm{~Hz}, \alpha$-anomeric proton).

Acetylation of $3 \mathrm{a}(100 \mathrm{mg})$ with acetic anhydride $(0.5 \mathrm{ml})$ and pyridine $(1 \mathrm{ml})$ afforded the acetate, PMR $\delta\left(\mathrm{CDCl}_{3}\right): 6.27(0.1 \mathrm{H}, \mathrm{d}, J=3.5 \mathrm{~Hz}, \alpha$-anomeric proton), $5.77(0.9 \mathrm{H}, \mathrm{d}, J=7.5 \mathrm{~Hz}, \beta$-anomeric proton).

Recrystallizations of the anomeric mixture twice from ethanol yielded $2 \mathrm{~g}$ of $\beta$-ester $(\beta-3 \mathrm{a})$, mp $130 \sim$ $131^{\circ} \mathrm{C}$. IR ${ }_{2 \max }^{\mathrm{KBr}} \mathrm{cm}^{-1}: 1740 . \quad \mathrm{NMR} \delta\left(\mathrm{CDCl}_{3}\right): 0.87$ $(3 \mathrm{H}, \mathrm{t}, J=7.5 \mathrm{~Hz}), 1.25(24 \mathrm{H}, \mathrm{s}), 1.62(2 \mathrm{H}, \mathrm{m}), 2.33$ $(2 \mathrm{H}, \mathrm{m}), 3.5 \sim 5.5$ (br), $5.45(1 \mathrm{H}, \mathrm{s}), 5.52(\mathrm{~d}, J=7.5 \mathrm{~Hz})$, $7.37(5 \mathrm{H}, \mathrm{s})$.

\section{1-O-Palmitoyl- $\beta$-D-glucopyranose (1a)}

a) Hydrogenolysis of $\beta$-3a. Benzylidene ester $\beta-3 \mathbf{a}$ $(500 \mathrm{mg}$ ) was dissolved in $10 \mathrm{ml}$ of dioxane containing a few drops of acetic acid and was shaken with $250 \mathrm{mg}$ of activated palladium black under hydrogen gas. The theoretical amount of hydrogen was absorbed during $24 \mathrm{hr}$ at room temperature. The catalyst was filtered off and the filtrate was concentrated in vacuo to yield palmitoyl glucose. Recrystallization from acetone afforded $400 \mathrm{mg}\left(97 \%\right.$ ) of $1 \mathrm{a}, \mathrm{mp} 107,172^{\circ} \mathrm{C}$ (double melting point). Tetraacetyl derivatives $(\beta-5 \mathrm{a}): \mathrm{mp} 71^{\circ} \mathrm{C}$.

b) Hydrolysis of $\beta \mathbf{- 3 a}$ with aqueous acetic acid. Benzylidene derivatives $(\beta-3 a)(2 \mathrm{~g}, 3.9 \mathrm{mmol})$ was dissolved in $70 \%$ acetic acid and was heated at $95^{\circ} \mathrm{C}$ for $1 \mathrm{hr}$. The reaction mixture was concentrated below $40^{\circ} \mathrm{C}$ in vacuo and was diluted with $5 \mathrm{ml}$ of methanol. To the methanol solution excess diazomethane in ether was added to methylate free palmitic acid caused by hydrolysis of the ester. After concentration of the mixture the residue was extracted with hexane, and the insoluble solid was chromatographed on silica gel $(9 \mathrm{~g})$ to yield $200 \mathrm{mg}$ of crystalline palmitoyl glucose by elution with chloroform-methanol (9:1). The crude ester was recrystallized from acetone to yield $160 \mathrm{mg}$ of $1 \mathrm{a}, \mathrm{mp} 106,165^{\circ} \mathrm{C}$ (double melting point $) .[\alpha]_{\mathrm{D}}^{20}-0.8^{\circ}(c=0.9, \mathrm{MeOH}) . \quad$ IR $\nu_{\max }^{\mathrm{KBr}} \mathrm{cm}^{-1}$ : 
1765, 1750, 1735. PMR $\delta\left(\left(\mathrm{CD}_{3}\right)_{2} \mathrm{CO}\right): 0.87(3 \mathrm{H}, \mathrm{t}$, $J=7 \mathrm{~Hz}), 1.26(24 \mathrm{H}, \mathrm{s}), 1.51(2 \mathrm{H}, \mathrm{m}), 2.36(2 \mathrm{H}, \mathrm{t}$, $J=8 \mathrm{~Hz}), 3.21(4 \mathrm{H}, \mathrm{m}), 3.5 \sim 3.8(6 \mathrm{H}, \mathrm{m}), 5.37(1 \mathrm{H}, \mathrm{d}$, $J=7 \mathrm{~Hz})$. CMR $\delta\left(\mathrm{DMSO}-d_{B}\right): 171.95(\mathrm{C}=\mathrm{O}), 94.35$ (Glucose 1-C), $78.02(\mathrm{G}-3), 76.63(\mathrm{G}-5), 72.68(\mathrm{G}-2)$, 69.71 (G-4), 60.85 (G-6), 33.67 (Palmitate 2'-C), 29.30 $\left(\mathrm{P}-4^{\prime} \sim 13^{\prime}\right), 24.39\left(\mathrm{P}-3^{\prime}\right), 22.33\left(\mathrm{P}-15^{\prime}\right), 14.08\left(\mathrm{P}-16^{\prime}\right)$, $31.61\left(\mathrm{P}-14^{\prime}\right)$. Tetraacetyl derivative $(\beta-5 \mathrm{a}): \mathrm{mp} 70^{\circ} \mathrm{C}$. IR $\nu_{\max }^{\mathrm{fimm}} \mathrm{cm}^{-1}: 1765,1750$. PMR $\delta\left(\mathrm{CDCl}_{3}\right): 5.73(\mathrm{~d}$, $J=7.5 \mathrm{~Hz}$ ). Anal. Found: C, $62.56 ; \mathrm{H}, 10.10$. Calcd. for $\mathrm{C}_{22} \mathrm{H}_{42} \mathrm{O}_{7} \cdot \mathrm{C}_{3} \mathrm{H}_{8} \mathrm{O}: \mathrm{C}, 62.99 ; \mathrm{H}, 10.15 \%$.

1,2-Di- $O$-palnitoyl- $\beta$-D-glucopyranose (2a) was obtained from the eluate with chloroform-methanol (19:1) and was recrystallized from ethyl acetate. PMR (TMS derivatives) $\delta\left(\mathrm{CCl}_{4}\right): 5.44(1 \mathrm{H}, \mathrm{d}, J=7.5 \mathrm{~Hz}$, changed to singlet by irradiation at 4.78$), 4.78(1 \mathrm{H}, \mathrm{t}$, $J=7.5 \mathrm{~Hz}$, changed to doublet by irradiation at 5.44 ).

1-O-Oleoyl-D-glucopyranose (1b). Sodium salt of 4,6- $O$-benzylidene-D-glucose ( $5 \mathrm{~g}, 17 \mathrm{mmol})$ was esterified with oleoyl chloride $(5.4 \mathrm{~g}, 17.9 \mathrm{mmol})$ in tetrachloroethane. The reaction mixture was filtered and concentrated, and the residue was twice chromatographed on silica gel $(100 \mathrm{~g})$. The oily product $3 \mathrm{~b}$ was obtained from the eluate with benzene-ethyl acetate $(7: 3)$. Yield: $1.2 \mathrm{~g}(14 \%)$. Acetyl derivative (4b): PMR $\delta\left(\mathrm{CDCl}_{3}\right): 6.46(0.17 \mathrm{H}, \mathrm{d}, J=3.5 \mathrm{~Hz}$, a-anomer), $5.85(0.83 \mathrm{H}, \mathrm{d}, J=7.5 \mathrm{~Hz}, \beta$-anomer $)$.

Benzylidene derivatives (3b) $(300 \mathrm{mg}$ ) was hydrolyzed in $50 \%$ acetic acid $(5.4 \mathrm{ml})$ for $1 \mathrm{hr}$ and the product was purified by preparative thin-layer chromatography (developed with chloroform-methanol $(4: 1))$ to yield $25 \mathrm{mg}(10 \%)$ of 1 b. IR $\nu_{\max }^{\text {film }} \mathrm{cm}^{-1}:$ 1740. PMR $\delta\left(\mathrm{DMSO}-d_{0}\right): 6.45(\mathrm{~d}, J=3.5 \mathrm{~Hz}), 5.26(\mathrm{~d}, J=7.5 \mathrm{~Hz})$. MS m/e $427\left(\mathrm{M}^{+}-18\right)$. Acetyl derivative (5b): PMR $\delta\left(\mathrm{CDCl}_{3}\right): 6.26(\mathrm{~d}, J=3.5 \mathrm{~Hz}), 5.75(\mathrm{~d}, J=7.5 \mathrm{~Hz})$. TMS derivatives: MS $m / e 743\left(\mathrm{M}^{+}+1\right)$.

3-O-Linolenoyl-D-glucopyranose $(9 \mathrm{c})$. Sadium salt of 4,6-O-benzylidene-D-glucose $(2.4 \mathrm{~g}, 8.2 \mathrm{mmol})$ and linolenoyl chloride $(2.4 \mathrm{~g}, 8.0 \mathrm{mmol})$ was reacted in tetrachloroethane. The product was chromatographed on silica gel to yield $1.6 \mathrm{~g}$ of crude ester. Rechromatography of crude ester with benzene-ethyl acetate as an eluent afforded $600 \mathrm{mg}$ of pure 4,6-O-benzylidene-1-Olinolenoyl- $\beta-\mathrm{D}$-glucopyranose $(3 \mathrm{c})$ as an oil. IR $\nu_{\max }^{\mathrm{film}}$ $\mathrm{cm}^{-1}: 3410,1764$. PMR ô $\left(\mathrm{CDCl}_{3}\right): 0.97(3 \mathrm{H}, \mathrm{t}, J=$ $7.4 \mathrm{~Hz}), 1.33(10 \mathrm{H}, \mathrm{s}), 1.82 \sim 2.53(6 \mathrm{H}, \mathrm{m}), 2.82(4 \mathrm{H}, \mathrm{t}$, $J=5.2 \mathrm{~Hz}), 3.3 \sim 4.5(9 \mathrm{H}, \mathrm{m}), 5.37(6 \mathrm{H}, t, J=4.7 \mathrm{~Hz})$, $5.48(1 \mathrm{H}, \mathrm{s}), 5.58(1 \mathrm{H}, \mathrm{d}, J=7.5 \mathrm{~Hz})$. Acetyl derivative (4c): PMR ô $\left(\mathrm{CCl}_{4}\right): 5.71(1 \mathrm{H}, \mathrm{d}, J=7.5 \mathrm{~Hz})$.

The benzylidene ester (3c) (500 $\mathrm{mg}, 0.94 \mathrm{mmol}$ ) was hydrolyzed in $50 \%$ acetic acid $(18 \mathrm{ml})$ at $95^{\circ} \mathrm{C}$ for $2 \mathrm{hr}$, and the reaction mixture was concentrated and purified by column chromatography on silica gel $(9 \mathrm{~g})$ to yield oily product $9 \mathrm{c}(105 \mathrm{mg})$ from the eluate with chloro- form-methand $(19: 1)$. IR $\nu_{\max }^{\operatorname{film}} \mathrm{cm}^{-1}: 3400,1735$. PMR $\delta\left(\mathrm{DMSO}-d_{\theta}\right): 0.97(3 \mathrm{H}, \mathrm{t}, J=7.5 \mathrm{~Hz}), 1.33(10 \mathrm{H}$, s), $1.36 \sim 1.72(2 \mathrm{H}, \mathrm{m}), 2.34(4 \mathrm{H}, \mathrm{t}, J=7.5 \mathrm{~Hz}), 2.82$ $(4 \mathrm{H}, \mathrm{t}, J=5 \mathrm{~Hz}), 3.05 \sim 3.85(\mathrm{~m}), 4.53(0.5 \mathrm{H}, \mathrm{d}, J=$ $7.5 \mathrm{~Hz}), 4.87(0.5 \mathrm{H}, \mathrm{t}, J=9.0 \mathrm{~Hz}), 5.09(0.5 \mathrm{H}, \mathrm{d}, J=$ $3.5 \mathrm{~Hz}), 5.14(0.5 \mathrm{H}, \mathrm{t}, J=9.0 \mathrm{~Hz}), 5.39(6 \mathrm{H}, \mathrm{m})$. CMR $\delta\left(\mathrm{DMSO}+\mathrm{D}_{2} \mathrm{O}\right): 174.98$ and $174.67(\mathrm{C}=\mathrm{O}), 132.69$ (16 C of Linolenate), 131.23 (L-9'), $129.23\left(\mathrm{~L}-10^{\prime}, 12^{\prime}\right)$, $128.74\left(\mathrm{~L}-13^{\prime}\right), 128.20\left(\mathrm{~L}-15^{\prime}\right), 97.87(1-\mathrm{C}$ of $\beta$ Glucosyl), $93.50(\mathrm{G}-\alpha-1), 78.93(\mathrm{G}-\beta-3), 77.54(\mathrm{G}-\beta-5)$, $76.81(\mathrm{G}-\alpha-3), 74.14(\mathrm{G}-\beta-2), 73.11(\mathrm{G}-\alpha-5), 71.71$ $(\mathrm{G}-\alpha-2), 60.77(\mathrm{G}-4), 62.37(\mathrm{G}-6), 35.43\left(\mathrm{~L}-3^{\prime}\right), 30.82$ and $30.46\left(\mathrm{~L}-5^{\prime}, 6^{\prime}\right.$ and $\left.7^{\prime}\right), 29.91\left(\mathrm{~L}-8^{\prime}\right), 28.33\left(\mathrm{~L}-4^{\prime}\right)$, 26.70 and $26.15\left(\mathrm{~L}-11^{\prime}\right.$ and $\left.14^{\prime}\right), 21.66\left(\mathrm{~L}-17^{\prime}\right), 15.35$ $\left(\mathrm{L}-18^{\prime}\right)$. MS m/e $423\left(\mathrm{M}^{+}-18\right)$. Acetyl derivative. PMR $\left(\mathrm{CCl}_{4}\right): 6.29(0.5 \mathrm{H}, \mathrm{d}, J=3.5 \mathrm{~Hz}), 5.65(0.5 \mathrm{H}, \mathrm{d}$, $J=7.5 \mathrm{~Hz})$. TMS derivative. PMR $\delta\left(\mathrm{CCl}_{4}\right): 4.96$ (t, $J=9.0 \mathrm{~Hz}$, coupled with 3.54$), 4.94(\mathrm{~d}, J=3.5 \mathrm{~Hz}$, coupled with 3.54$), 4.75(\mathrm{t}, \mathrm{m}, J=9.0 \mathrm{~Hz}$, coupled with $3.33), 4.48(\mathrm{~d}, \mathrm{~d}, J=7.5,2.0 \mathrm{~Hz}$, coupled with 3.33$)$, $3.54(\mathrm{~d}, \mathrm{~d}, J=9.0,3.5 \mathrm{~Hz})$. MS $m / e 736\left(\mathrm{M}^{+}+1\right)$.

3-O-Linolenoy $-\mathrm{D}-$ glucopyranose $(9 \mathrm{c})$ from diacetone glucose (11). Chloroform solution $(30 \mathrm{ml})$ of 1,2 ; 5,6-di- $O$-isopropylidene- $\alpha$-D-glucofuranose (11) $(1.5 \mathrm{~g}$, $5.8 \mathrm{mmol})$ and pyridine $(0.64 \mathrm{~g}, 8.1 \mathrm{mmol})$ was treated with $1.9 \mathrm{~g}$ of linolenoyl chloride $(6.4 \mathrm{mmol})$. After standing overnight at room temperature, $5 \mathrm{ml}$ of methanol was added to the solution. The reaction mixture was filtered and concentrated in vacuo and the residue was subjected to column chromatography on silica gel $(30 \mathrm{~g})$ to yield linolenoyl ester $(10 \mathrm{c})$ from the eluate with benzene. Yield $2.9 \mathrm{~g}(90 \%)$. IR 2 inmax $\mathrm{cm}^{-1}$ : 1755. NMR $\delta\left(\mathrm{CDCl}_{8}\right): 0.90(3 \mathrm{H}, \mathrm{t}, J=7.5 \mathrm{~Hz}), 1.24$ $(10 \mathrm{H}, \mathrm{s}), 1.33(6 \mathrm{H}, \mathrm{s}), 1.44(6 \mathrm{H}, \mathrm{s}), 1.8 \sim 2.5(\mathrm{~m}), 2.73$ $(4 \mathrm{H}, J=5.0 \mathrm{~Hz}), 3.5 \sim 4.5(\mathrm{~m}), 5.23(6 \mathrm{H}, \mathrm{t}, J=3.3 \mathrm{~Hz})$, $5.73(1 \mathrm{H}, \mathrm{d}, J=3.5 \mathrm{~Hz})$.

To a solution of di-O-isopropylidene-linolenate $(10 \mathrm{c})$ $(520 \mathrm{mg}, 1 \mathrm{mmol})$ in $5 \mathrm{ml}$ of ether was added $5 \mathrm{ml}$ of conc. hydrochloric acid at $0^{\circ} \mathrm{C}$. After stirring for $1 \mathrm{hr}$ at $10^{\circ} \mathrm{C}$, the reaction mixture was diluted with $10 \mathrm{ml}$ of water and extracted with ether $(20 \mathrm{ml})$. The extract was concentrated in vacuo and the residue was purified by silica gel column chromatography. 3-OLinolenoyl-glucopyranose (9c) was obtained from the eluate with chloroform-methanol $(9: 1)$; yjeld $360 \mathrm{mg}$ $(85 \%)$

\section{3-O-Stearoyl-D-glucopyranose (9d)}

a) Synthesis from diacetone glucose. Dry 1,2;5,6di-O-isopropylidene- $\theta$-D-glucofuranose $(11)$ was allowed to react with stearoyl chloride in chloroform in the presence of pyridine. The chloroform soluble portion of the reaction mixture was chromatographed on silica gel. Stearate $10 \mathrm{c}$ was eluted with benzene and crystallized from benzene-hexane, $\mathrm{mp} 92,101^{\circ} \mathrm{C}$ (double melting point). 
The protecting group of $10 \mathrm{c}$ was removed with hydrochloric acid. Stearoyl glucose was purified by column chromatography on silica gel (eluted with chloroformmethanol $(9: 1)$ and crystallized from methanol, mp130, $162^{\circ} \mathrm{C}$ (double melting point).

b) Hydrogenolysis of 3-O-linolenoyl-D-glucopyranose (9c). 3-O-Linolenoyl-D-glucopyranose (9c) ( $30 \mathrm{mg}$ ), which was obtained by hydrolysis of benzylidene derivatives, was dissolved in $10 \mathrm{ml}$ of methanol and was hyderogenated over $10 \mathrm{mg}$ of palladium-black. The calculated amounts of hydrogen was smoothly absorbed during $30 \mathrm{~min}$. The shaking was continued for $2 \mathrm{hr}$ and the catalyst was filtered off. After removal of methanol the residual solid was recrystallized from methanol to yield $20 \mathrm{mg}(96 \%)$ of $9 \mathrm{~d}, \mathrm{mp} 118,159^{\circ} \mathrm{C}$, mixed $\mathrm{mp}$ with authentic sample, $120,161^{\circ} \mathrm{C}$.

Pollen Germination Test. The ripe anthers of tobacco (Nicotiana tabacum L. Bright yellow) and rape (Brassica napus L.) were collected.

The isotonic solution ( $8 \mathrm{M}$ sucrose, $\mathrm{pH} 7,0.2 \mathrm{ml}$ ) containing 3-O-linolenoyl-D-glucopyranose (9c) was kept in glass vessel and cooled to $5^{\circ} \mathrm{C}$. Six anthers of tobacco were suspended in the culture fluid and shaken to wash out the pollens. The culture fiuid suspending pollens was kept in dark at $22^{\circ} \mathrm{C}$ for $3 \sim 4 \mathrm{hr}$ (for $12 \mathrm{hr}$ in the case of rape pollen). One drop of the fluid was placed on a slide glass and observed under a microscope. The number of pollens with any germinated pollen tubes were counted as germinated pollens, and pollens with pollen tubes longer than twice the length of their width were counted as elongated pollen tubes. Pollens with burst pollen tubes were included in elongated pollen tubes. All experiments were conducted with three replications. Germination rate and percent of pollens with elongated pollen tubes were calculated from the average values of three reprications for each concentration by use of $150 \sim 500$ pollens in each measurement. The difference in each measurement could be regarded as significant in $5 \%$ level.

Acknowledgment. The authors express their thanks to Dr. T. Hinata, Tohoku University for his valuable advice about bioassay of pollen. The supply of fatty acid by Nisshin Seiyu Co. Ltd., is gratefully acknowledged.

\section{REFERENCES}

1) J. W. Mitchell, N. Mandava, J. F. Worley, J. R. Plimmer and M. V. Smith, Nature, 225, 1065 (1970); M. Mandava, B. A. Sidwell, J. M.Mitchell and J. F. Worley, Ind. Eng. Chem. Prod. Res. Develop, 12, 138 (1973); J. W. Mitchell, L. E. Gregory, Nature New Biology, 239, 253 (1972); J. W. Mitchell, N. Mandava, J. F. Worley and M. E. Drowne, J. Agric. Food Chem., 19, 391 (1971).

2) N. Mandava and J. W. Mitchell, Chem. Ind., $1972,930$.

3) M. D. Grove, G. F. Spencer, P. E. Pfeffer, N. Mandava, J. D. Warthen Jr. and J. F. Worley, Phytochemistry, 17, 1187 (1978).

4) A. Kobayashi, K. Watanabe and K. Yamashita, Agric. Biol. Chem., 36, 2151 (1972).

5) M. Smith, D. H. Rammler, I. H. Goldberg and H. G. Khorana, J. Am. Chem. Soc., 85, 3821 (1963); R. M. Hann, N. K. Richtmyer, H. W. Diehl and C.S. Hudson, ibid., 72, 561 (1950); R. K. Ness, Methods Carbohydr. Chem., 1, 90 (1962); R. W. Jeanloz, ibid., 1, 234 (1962).

6) H. G. Fletcher Jr., ibid, , 2, 231 (1963).

7) P. E. Pfeffer, E. S. Rothman and G. G. Moore, J. Org. Chem., 41, 2925 (1976).

8) Y. Nishikawa and K. Yoshimoto, Chem. Pharm. Bull., 25, 624 (1977).

9) C. E. Redemann and C. Niemann, Org. Syn., III, 11 (1955).

10) C. M. McCloskey and G. H. Coleman, ibid., III, 434 (1955).

11) M. R. Vignon and Ph. J. A. Vottero, Tetrahedron Lett., 1976, 2445.

12) R. Hori and T. Koizumi, Yakugakuzasshi (Jpn), 78, 1003 (1958).

13) H. O. L. Fischer and C. Taube, Ber, 60, 488(1927).

14) J. W. Mitchell, G. D. York and J. F. Worley, J. Agric. Food Chem., 15, 329 (1967).

15) T. Hoshi and Y. Hinata, Ikushuzasshi, 24, (extra number 2) 188 (1974). 